\title{
Embryonic expression of a Drosophila src gene: alternate forms of the protein are expressed in segmental stripes and in the nervous system
}

\author{
Walter S. Vincent III, Richard J. Gregory, and Samuel C. Wadsworth' \\ Cell Biology Group, Worcester Foundation for Experimental Biology, Shrewsbury, Massachusetts 01545 USA
}

\begin{abstract}
Expression of the Drosophila src-related gene, Dsrc28C has been investigated at the protein level using monoclonal antibodies. This analysis has revealed that the Dsrc28C gene encodes two protein forms: a 66-kD doublet predicted from the sequence of a cDNA clone and an additional $55-\mathrm{kD}$ form. The 66-kD protein doublet is observed first at the cellular blastoderm stage and is not detectable in embryos after $12 \mathrm{hr}$ of development. Expression of the 55-kD protein lags behind that of the 66-kD doublet and then persists throughout embryogenesis. Indirect immunofluorescence microscopy reveals that Dsrc28C protein is localized to the cell periphery during cellular blastoderm and gastrulation. The cell periphery-associated staining is then resolved into ectodermal stripes along the fully extended germ band. After the stripes fade, cytoplasmic staining of the majority of cells within the central and peripheral nervous system is observed. The 66-kD protein was shown to represent the cell periphery-associated form of the protein through antibody staining of larval salivary glands expressing a heat shock promoter-driven, full-length Dsrc28C cDNA. Staining of embryos with a monoclonal antibody specific for the $66-\mathrm{kD}$ protein indicates that the $55-\mathrm{kD}$ protein is the nervous system form. Thus, the 66- and 55-kD proteins are products of the Dsrc28C gene, which exhibit different temporal and spatial patterns of expression in the embryo.
\end{abstract}

[Key Words: src; oncogene; Drosophila; development; segmentation; nervous system]

Received September 19, 1988; revised version accepted January 26, 1989.

The src gene family represents the largest and perhaps the most completely characterized group of oncogenes. The original member of this family, the v-src gene, transduced by Rous sarcoma virus, is known to have protein tyrosine kinase activity that is necessary for oncogenic potential. Additional members of this extensive gene family have been revealed through several routes (for review, see Hanks et al. 1988). First, additional srcrelated genes were found using the portion of the gene encoding the catalytic portion of the enzyme, the 'kinase domain', as a hybridization probe to search genomic or cDNA libraries. Comparison of sequences from such related genes has allowed identification of highly conserved and, presumably, universally functional domains of the src protein (Van Beveren and Verma 1986; Hanks et al. 1988). Second, numerous genes identified through genetic techniques in invertebrates, when cloned and sequenced, were found to possess amino acid sequence homology with the kinase domain of src. Protein tyrosine kinase or protein serine/ threonine kinase activity has been demonstrated

\footnotetext{
'Corresponding author.
}

directly for proteins encoded by genes isolated through each of the above strategies (Reed et al. 1985; Henkemeyer et al. 1988). It is assumed that proteins encoded by other src family members also possess protein kinase activity because specific amino acid positions within the kinase domain are conserved. Similarly, there are examples of both vertebrate and invertebrate src family members that perform regulatory functions in cell physiology. In vertebrates, the clearest examples of regulatory members of the src family are the peptide growth factor receptors that function in signal transduction in response to extracellular stimuli. Notable examples of invertebrate $s r c$-related genes identified through their regulatory phenotypes are the cell-division control gene CDC28 in Saccharomyces cerevisiae (Lorincz and Reed 1984) [cdc2 in Saccharomyces pombe (Beach et al. 1982)] and a cellular level homeotic gene, sevenless, in Drosophila melanogaster (Banerjee et al. 1987; Hafen et al. 1987). The latter gene encodes a protein with a src-related kinase domain and a large extracellular domain, a structure reminiscent of vertebrate growth factor receptors. Expression of the sevenless gene in developing ommatidia determines whether precursor cells will differentiate into R7 photoreceptor cells or lens-secreting 
cone cells (Tomlinson and Ready 1986). An important recent finding is that site-directed mutagenesis of the kinase domain inactivates sevenless function (Basler and Hafen 1988).

We have been studying a Drosophila src-related gene, referred to as Dsrc28C. This gene was isolated by low stringency hybridization with a probe representing the kinase domain of v-src and shown to be related most closely to v-src and other tyrosine kinases on the basis of key residues within the kinase domain (Wadsworth et al. 1985; Gregory et al. 1987). Therefore, it is likely that the Dsrc28C protein possesses intrinsic protein kinase activity. Although Dsrc28C represents a mainstream src family member when highly conserved amino acids are considered, it is a unique member of this gene family by other criteria. The overall sequence, as well as the structure of the protein, is significantly different from other $s r c$ family proteins. Most notably, the Dsrc28C protein is extremely basic with a $\mathrm{pI}$ of $\sim 10$. An additional unusual feature of the protein is an amino-terminal domain of 27 amino acids that is $74 \%$ glycine (Gregory et al. 1987). Expression of the gene has been characterized at the RNA level. Dsrc28C transcripts are inherited maternally and expressed during much of embryogenesis but are not abundant during any other developmental stage, suggesting a largely embryonic function for the gene (Wadsworth et al. 1985; Gregory et al. 1987). Because tissue in situ hybridization studies did not reveal preferential RNA expression during embryogenesis, it has not been possible to implicate Dsrc28C in any particular developmental process.

To allow a more direct and higher resolution analysis of embryonic expression of Dsrc28C, we have produced monoclonal antibodies to document the temporal and spatial expression of the proteins encoded by the Dsrc28C gene. We report here that Dsrc28C proteins are expressed first in all ectodermal cells, then in a segmentally striped array in extended germ-band embryos, and later on, in the nervous system. In addition, unique forms of the protein are correlated with either ectodermal or nervous system expression. These results suggest that separate forms of the Dsrc28C protein are involved in segmentation and neuronal differentiation.

\section{Results \\ Generation of monoclonal antibodies specific for the Dsrc28C protein}

Monoclonal antibodies (mAbs) were produced against a bacterially expressed form of the Dsrc28C protein, referred to as plac28C, encoded by the expression plasmid shown in Figure $1 \mathrm{~B}(1)$. The protein produced from this vector contains all of the amino acids encoded by a fulllength Dsrc28C cDNA clone (Gregory et al. 1987), as well as 33 amino-terminal residues derived from the polylinker region of the expression vector. mAbI19, which was used for most of the experiments, reacts on immunoblots with plac28C from IPTG-induced plasmidbearing cells (Fig. 2, lane 1) but not with IPTG-induced proteins from control cells (Fig. 2, lane 6). Additional cDNA expression plasmids were constructed (Fig. 1B) to define the portion of the Dsrc28C protein recognized by mAbI19. The proteins produced by these plasmids are shown also in Figure 2 . mAbI19 reacts with the proteins produced from plac28C-S containing Dsrc28C amino acids 126-590 (lane 2), pWV404 containing Dsrc28C amino acids $42-590$ (lane 3 ), and pWV406 containing Dsrc28C amino acids 42-381 (lane 5) but does not react with protein produced from pWV405 containing Dsrc28C amino acids 409-590 (lane 4). Therefore, the portion of the Dsrc28C protein recognized by mAbIl9 is located between amino acids 126 and 381 .

\section{mAbI19 reacts with two major forms of the Dsrc28C protein in embryos}

Because Dsrc28C transcripts are most abundant during embryogenesis, immunoblot experiments were performed on protein prepared from a variety of embryonic stages. Two major protein species were detected with mAbI19: a closely-spaced doublet of $\sim 66-\mathrm{kD}$ (referred to hereafter as p66) and a protein of $\sim 55-\mathrm{kD}$ (referred to hereafter as p55) (Fig. 3). The reason for the appearance of $\mathrm{p} 66$ as a doublet is unknown. Whether expressed from the Dsrc28C gene or from a heat shock promoter-driven full-length cDNA (Fig. 4A), this protein always appears as a doublet; for convenience, both proteins in this dou-

Figure 1. (See p. 336.) Dsrc28C expression vectors. $(A)$ Dsrc28C cDNA map. (B) Expression vectors used for production of Dsrc28C proteins in bacteria. (1) plac28C expression vector. The ATGl codon is believed to be the normal initiator codon for the p66 Dsrc28C protein. Initiation of translation in bacteria takes place at the upstream lac ATG. (2) The plac28C-S expression vector. ATG is the lac initiator codon and is used for translational initiation of plac28C-S. ATG3 corresponds to the third methionine codon in the cDNA. It is the second in-frame methionine codon in this construct and is used for translational initiation of p28C-S. Independent initiation occurs at both of these codons in SupE44-bearing strains of E. coli (see text for details). (3-5) pWV404, pWV405, and pWV406 expression vectors, respectively. For each of these vectors, initiation of translation in bacteria takes place at the upstream lac ATG. (C) P-element-based expression vectors used to produce Dsrc28C proteins in flies. (1) pCasper-hs $28 \mathrm{C}$ P-element expression vector. The initiator codon shown (ATG1) is believed to be the normal one for the p66 Dsrc28C protein. The consensus poly(A) addition sequence shown is from a Drosophila hsp70 gene. (2) pCasper-hs28C-S P-element expression vector, which was generated from pCasper-hs $28 \mathrm{C}$ by deleting a HindIII fragment that contained the normal initiator methionine codon for p66. ATG3 serves as the initiator codon. In all cases, the terminator codon shown is the one encoded by the full-length Dsrc28C cDNA. 
Vincent et al.

blet will be referred to as p66. A minor protein of $~ 95-$ $\mathrm{kD}$ is recognized also by mAbI19 and by another monoclonal antibody raised against plac28C (mAbB3). The ap- pearance of the $95-\mathrm{kD}$ protein always parallels the appearance of $\mathrm{p} 66$. It is not known whether this protein represents an aggregate of $\mathrm{p} 66$ or another form of protein

A. Dsrc 28C CDNA

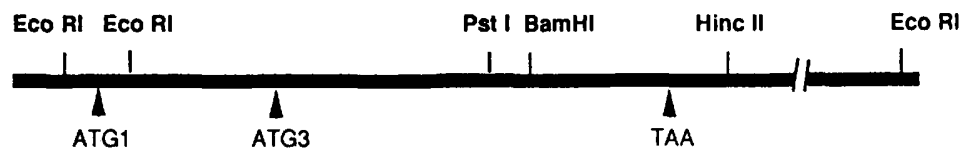

B. E. coli protein expression

(1)

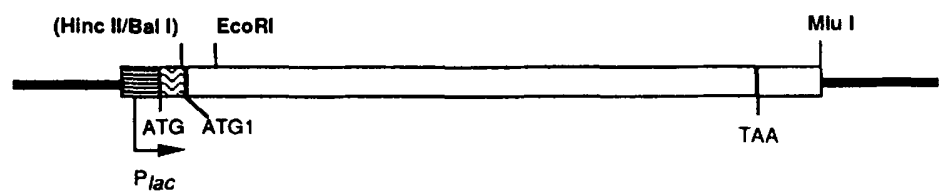

(2)

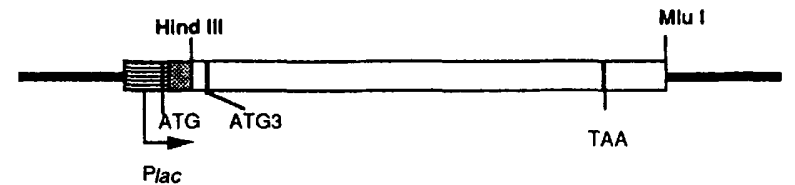

(3)

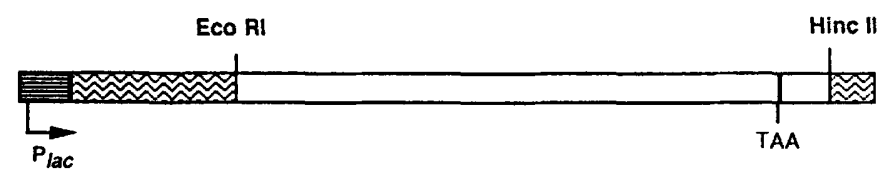

(4)

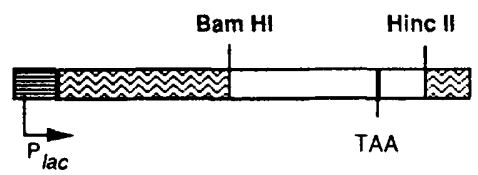

(5)

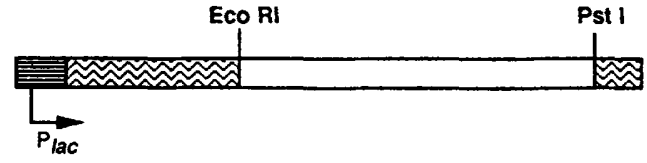

C. P element transformation

(1)

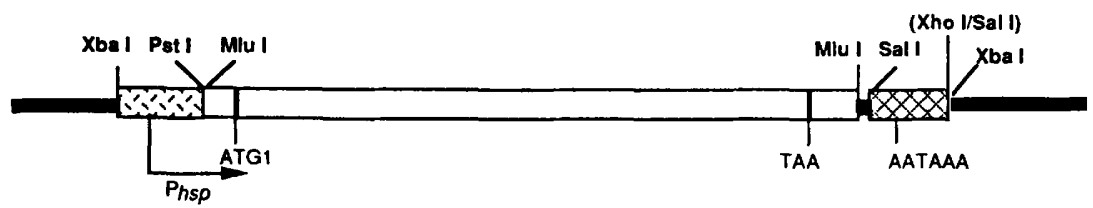

(2)

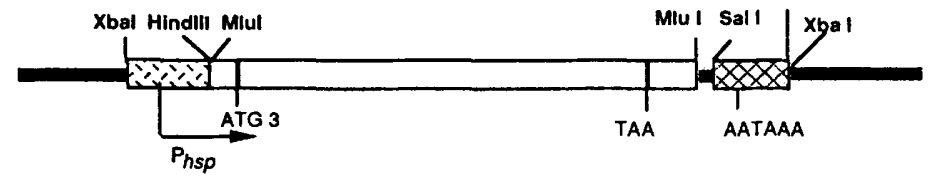

Vectors

Promotors

Other DNAs

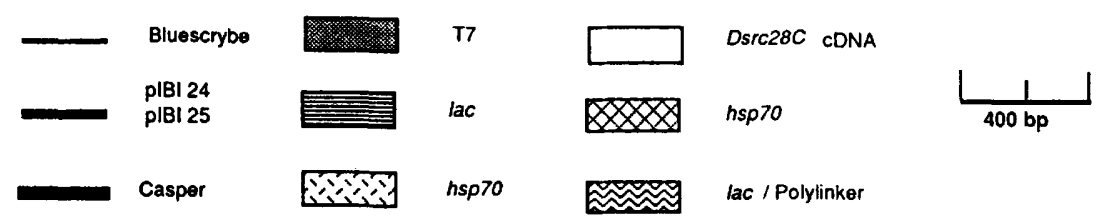

Figure 1. (See preceding page for legend.) 


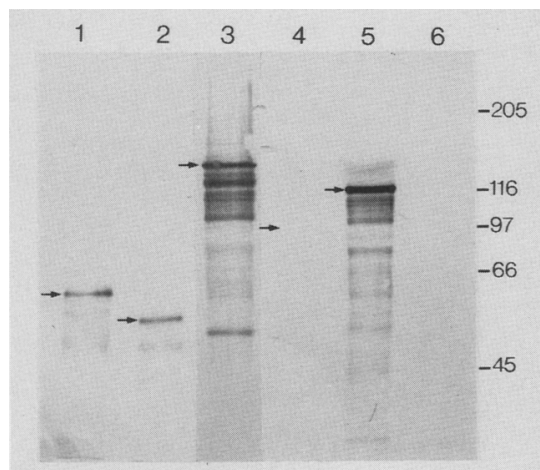

Figure 2. Dsrc28C proteins produced by $E$. coli expression vectors. Insoluble proteins prepared from the expression vectors diagramed in Fig. 1B were electrophoresed through an $8 \%$ SDS-polyacrylamide gel, transferred to nitrocellulose, and reacted with mAbI19. Lanes 1-5 correspond to the expression vectors numbered within Fig. 1B. (Lane 6) Proteins from the host bacterial strain alone (XL1-Blue, Stratagene) were electrophoresed. Arrows indicate the positions of the primary IPTGinduced translation products from the expression vectors. Note that mAbI19 does not react with the pWV405 fusion protein containing the carboxy-terminal portion of Dsrc28C (lane 4). Lower molecular weight antibody-reactive proteins are presumably breakdown products. (right) Positions and relative molecular weights of marker proteins electrophoresed in a parallel lane.

produced by the Dsrc28C gene. The low level of expression of this protein has precluded its further characterization. p66 is not detected in preblastoderm embryos; peak expression is observed between 8 and $10 \mathrm{hr}$ of embryogenesis, followed by an abrupt decline by $14 \mathrm{hr}$ of

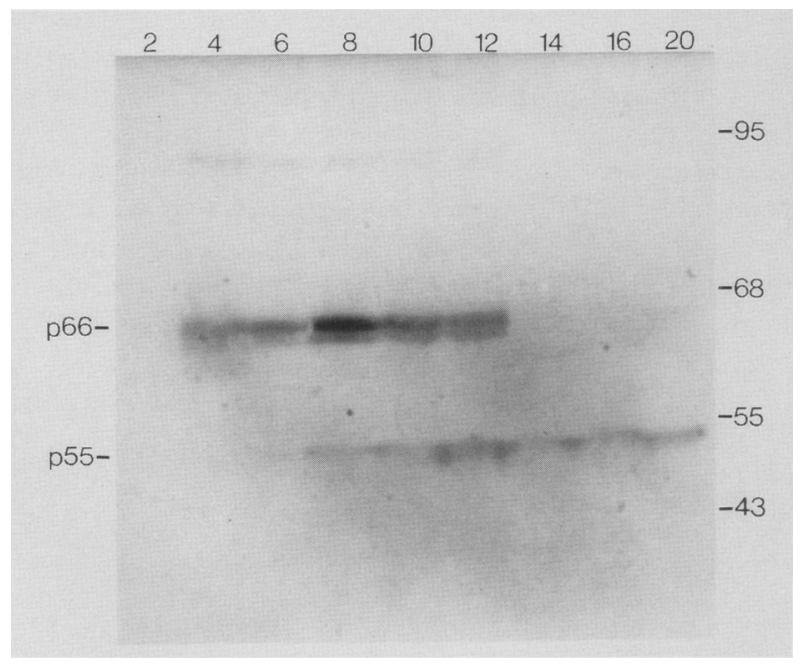

Figure 3. Developmental expression of Dsrc28C proteins. Whole embryo protein $(\sim 100 \mu \mathrm{g} /$ lane) from the indicated stages was subjected to SDS-PAGE and immunoblotting, as described in Methods. (p66 and p55) Predicted molecular weights of the alternate forms of Dsrc28C proteins discussed in this paper; they were not derived from their migration relative to the proteins of known size. (Right) Positions and relative molecular weights of marker proteins electrophoresed in a parallel lane used to estimate the sizes of the Dsrc28C proteins. (Top) Hours since egg deposition.

embryogenesis. p55 is detected first at $\sim 4-6 \mathrm{hr}$ of embryogenesis, reaching its highest levels at a time when expression of the p66 doublet is declining, and persists throughout the remainder of embryogenesis. As noted above, previously we have characterized expression of

Figure 4. Correspondence between embryonic and recombinant Dsrc28C proteins. $(A)$ Comigration of Dsrc28C protein produced from cloned cDNAs and that produced in embryos from the genomic Dsrc28C locus. mAbI19-reactive proteins produced from pCasper-hs $28 \mathrm{C}$, either in the absence of heat shock (lane 1) or after heat shock (lane 2). (Lane 3) mAbI19-reactive proteins from 12-hr embryos. mAbI19-reactive proteins produced from pCasper-hs $28 \mathrm{C}-\mathrm{S}$, either in the absence of heat shock (lane 5) or after heat shock (lane 4). The positions of p66 and p55 are indicated. $(B)$ Immunoblot of V8 protease digestion products of embryonic p66 (lane 1) and the protein produced from pCasper-hs $28 \mathrm{C}$ (lane 2). Dashes indicate positions of the major comigrating mAbI19reactive digestion products. The arrowhead indicates the position of undigested p66. $(C)$ Immuno-

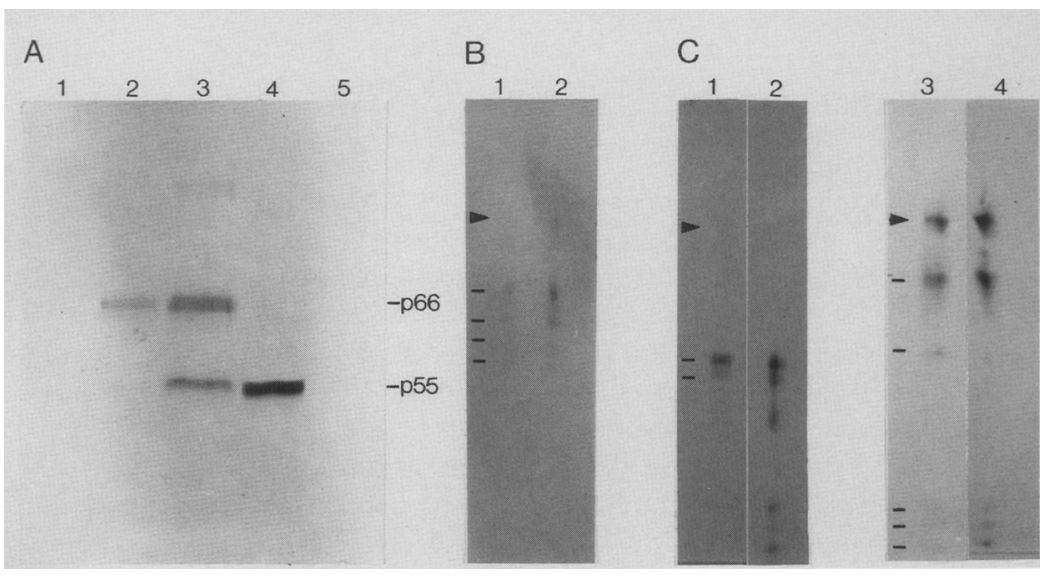
blot of protease digestion products from embryonic p55 (lanes 1,3) and the protein produced from pCasper-hs $28 \mathrm{C}-\mathrm{S}($ lanes 2,4). (Lanes $1,2)$ V8 digestion products; (lanes 3,4 ) chymotrypsin digestion products. Dashes indicate the positions of major comigrating mAbIl9reactive digestion products. In the case of V8 protease, additional minor common digestion products were observed on the original immunoblot. The arrowhead indicates the position of undigested p55. 
the Dsrc28C gene at the RNA level (Gregory et al. 1987). Although Dsrc28C transcripts are inherited maternally, the results presented in Figure 3 indicate that significant levels of maternal protein are not present in the preblastoderm embryo. Also, we have shown previously that maternal Dsrc28C transcripts are polyribosome associated (Wadsworth et al. 1985). Taken together, these results indicate that Dsrc28C transcripts deposited in the oocyte represent classical masked maternal mRNA. Dsrc28C transcripts are present throughout much of embryogenesis but decline sharply in abundance between 10 to $19 \mathrm{hr}$. Thus, the expression of mAbI19-reactive proteins correlates well with our previous characterization of Dsrc28C RNA expression.

\section{Both mAbI19-reactive proteins are encoded by the Dsrc28C gene}

Several experimental approaches were taken to prove that the embryo proteins recognized by mAbI19 are authentic Dsrc28C gene products. A full-length Dsrc28C cDNA under the control of an hsp70 promoter [pCasperhs28C, Fig. 1C(1)] was introduced into the germ line of flies by P-element transformation. pCasper-hs $28 \mathrm{C}$ directs the synthesis of an mAbI19-reactive protein doublet under heat shock conditions in adult flies, which is electrophoretically indistinguishable from the embryonic p66 (Fig. 4A, lane 2,3). In the absence of heat shock, significant amounts of $\mathrm{mAbI} 19$-reactive protein are not observed in pCasper-hs28C-bearing adult male flies (Fig. $4 \mathrm{~A}$, lane 1). In addition, embryonic p66 and the proteins encoded by the pCasper-hs $28 \mathrm{C}$ construct yield identical protease V8 digestion products (Fig. 4B). On the basis of these experiments, we conclude that the proteins in the p66 doublet are products of the Dsrc28C gene and are encoded by the mRNA represented by the cDNA clone that we have characterized previously (Gregory et al. 1987).

If $\mathrm{p} 55$ is encoded by the Dsrc $28 \mathrm{C}$ gene, it could come from an alternate mRNA species, from alternate translational initiation of the same mRNA, or from cleavage of p66. A clue to the origin of $\mathrm{p} 55$ came from the observation that cell-free translation of in vitro transcripts from the Dsrc28C cDNA yields a second major protein of $\sim 55-\mathrm{kD}$, which could arise from initiation at the third methionine codon (Gregory et al. 1987). To allow a definitive test of the hypothesis that $\mathrm{p} 55$ arises from initiation at the third methionine codon within the Dsrc28C sequence, a heat shock promoter-driven expression vector (pCasper-hs $28 \mathrm{C}-\mathrm{S}$ ) containing a truncated version of the cDNA was constructed [Fig. 1C(2)]. In this construct, the first two methionine codons have been eliminated, leaving the former third methionine codon as the first in-frame methionine codon. The sequence around this methionine codon represents a characteristic initiator codon, as described by Kozak (1987) and modified for Drosophila by Cavener (1987). An additional out-offrame methionine codon that does not resemble an initiator codon is retained in the truncated cDNA. Beyond the amino-terminal truncation site, the sequences in
pCasper-hs28C-S are identical to the full-length Dsrc28C cDNA. The protein encoded by pCasperhs $28 \mathrm{C}-\mathrm{S}$ is electrophoretically indistinguishable from embryonic p55 (Fig. 4A, lanes 3,4) and is not produced at significant levels in non-heat-shocked pCasper-hs28C-Sbearing adult male files (Fig. 4A, lane 5).

A further comparison between embryonic p55 and that directed by the truncated cDNA sequences in pCasper-hs $28 \mathrm{C}-\mathrm{S}$ clone was made through mapping of V8 protease and chymotrypsin cleavage sites. pCasperhs $28 \mathrm{C}-\mathrm{S}$ protein and the late embryo p55 were isolated on SDS-polyacrylamide gels and subjected to cleavage with either V8 protease or chymotrypsin during electrophoresis on a second SDS-acrylamide gel as described by Cleveland et al. (1977). The cleavage products were detected by mAbI19 reactivity after transfer to nitrocellulose. The major V8 protease (Fig. 4C, lanes 1,2) and chymotrypsin (Fig. 4C, lanes 3,4) cleavage products of the embryo p55 and pCasper-hs $28 \mathrm{C}-\mathrm{S}$ comigrate. We conclude from these results that $\mathrm{p} 55$ is encoded by the Dsrc28C gene, presumably resulting from translational initiation at the third methionine codon in the cDNA sequence. This point will be discussed further below.

\section{Distribution of Dsrc28C protein during early embryogenesis}

To define the distribution of the Dsrc28C proteins, whole embryos of various stages were stained with mAbI19 after fixation and devitellinization (Thomas et al. 1988). No significant staining of preblastoderm embryos is observed (data not shown), in agreement with the lack of detectable Dsrc28C protein in 0- to 2-hr embryos by immunoblot experiments (Fig. 3). At the cellular blastoderm stage, a reticular pattern of mAbIl 9 staining is observed evenly distributed over the embryo (Fig. 5a). A higher magnification view of this pattern over the central portion of an embryo is shown in the upper portion of Figure 5b. Also shown in the lower portion of Figure $5 \mathrm{~b}$ is an embryo (outlined with dashes) that was processed in parallel with the embryo in the upper portion and was stained only with the fluorescent second antibody. Thus, the intense reticular staining pattern observed in embryos is dependent on mAbI19. Closer examination of a focal plane near the center of a similar embryo (Fig. 5c) reveals that the staining giving rise to the reticular pattern is distributed uniformly around the periphery of cells. This pattern of peripheral intracellular staining persists through gastrulation (Fig. $5 \mathrm{~d}$, an example of an early gastrula) and early germ-band extension (data not shown).

The germ band of a Drosophila embryo is the ventral region between the cephalic furrow and the posterior pole that gives rise to the segments of the head, thorax, and abdomen. Between 3.5 and $5.5 \mathrm{hr}$ of embryogenesis, the germ band extends around the posterior end of the embryo such that the former posterior pole is located near the head. Around the time of full germ-band extension, a dramatic change in the pattern of mAbIl9 staining takes place: stripes of antibody staining appear 

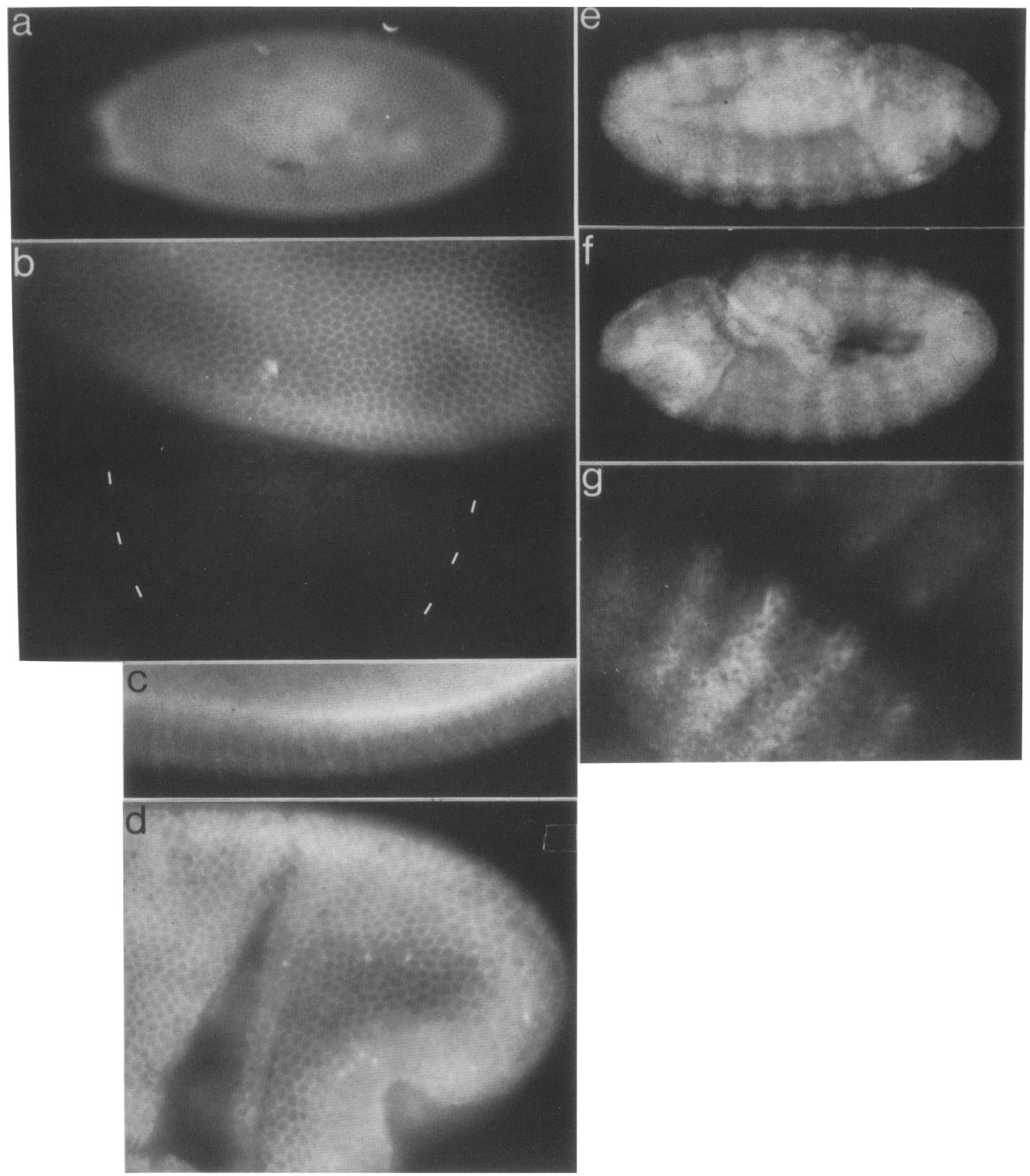

Figure 5. Indirect immunofluorescence staining of early embryos with mAbI19. Whole Drosophila embryos were stained with mAbI19 after removal of the chorion and vitelline membrane and subsequently stained with fluorescent second antibody. $(a)$ Surface focal plane of a cellular blastoderm embryo. Anterior is to the left; $(b, t o p)$ A higher magnification view of a cellular blastoderm

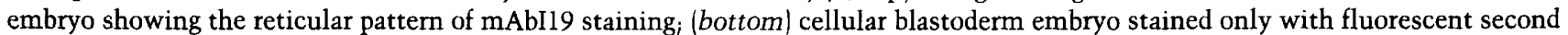
antibody (outlined by hash marks). No significant antibody staining is observed; (c) A higher magnification view of a cellular blastoderm embryo at the focal plane of the middle of the embryo. Immunofluorescence is observed surrounding cells of the ectoderm; $(d)$ Surface focal plane of the anterior end of an early gastrula (stage 7 or early stage 8$) ;(e, f)$ Two different embryos with fully extended germ bands (stage 11). The dorsal side is up in both embryos. Anterior is to the right in $e$ and to the left in $f$. $(g)$ Higher magnification view of mAbI19 staining stripes. 
over the germ band (Fig. $5 \mathrm{e}-\mathrm{g}$ ). In addition to staining of portions of the head region, 13 or 14 stripes are observed routinely (Fig. 5e,f). The uncertainty in the number of antibody staining stripes is due to variable observation of the most posterior stripe.

Three points about the nature of the Dsrc28C stripes should be emphasized. First, mAbI19 staining still is restricted to the periphery of ectodermal cells at this stage (Fig. 5g). Second, the striped pattern is extremely transient in nature. The first suggestion of stripes is observed in embryos with a completely extended germ band and the striped pattern fades within an hour, as determined by examination of synchronized embryo populations. By the time germ-band retraction begins $(2 \mathrm{hr}$ after full germ-band extension) and the stripes have faded, mAbI19 staining of the periphery of ectodermal cells, in general, has decreased greatly. Third, the stripes are faint, even at their peak expression and are separated by interstripe regions characterized by less intense but observable staining. Although these factors make it difficult to assess stripe width accurately, we believe that the most intense mAbI19 staining defines stripes of approximately two to three cells, separated by less intensely stained interstripes of three to four cells (Fig. 5g).

\section{Dsrc28C is expressed in the nervous system}

After mAbI19 staining of ectodermal cells fades, totally different pattern of antibody staining is observed: mAbI19 specifically stains cells of the nervous system. In addition, the antibody staining is no longer restricted to the periphery of the cell but, instead, seems to redistributed throughout the cytoplasm. Two typical mAbI19-stained embryos are shown in Figure 6a. In the embryo on the left, mAbIl9 staining is distributed evenly along the central nervous system (CNS). In the embryo on the right $(\sim 5 \mathrm{hr}$ older), substantial central nerve cord condensation has occurred and all portions of the CNS still have stained uniformly with mAbI19. Uniform staining of the CNS is observed until the end of embryogenesis and in first instar larvae as well (data not shown).

Staining of embryos with antibody recognizing horseradish peroxidase (HRP) was carried out in parallel to identify the nervous system (data not shown). Anti-HRP fortuitously recognizes an antigen present in the Drosophila CNS and the peripheral nervous system (PNS) (Jan and Jan 1982). Closer examination revealed that mAbI19 not only stains the CNS but also stains neurons of the PNS. Ventral groups of segmental peripheral neurons staining with mAbI19 can be seen in Figure $6 \mathrm{~b}$, whereas other more lateral groups are shown in Figure 6c. No attempt was made to identify precisely the peripheral neurons staining with $\mathrm{mAbI} 19$. The diffuse cytoplasmic nature of mAbIl9 staining of the nervous system also can be seen in the peripheral neurons. Thus, a large fraction of cells within the CNS and PNS express Dsrc28C proteins.
The Dsrc28C p66 protein represents the cell periphery form

The results presented so far allowed us to conclude that two major forms of the Dsrc28C protein are present during embryonic development and that Dsrc28C proteins are distributed in two different patterns. To determine which mAbI19 staining pattern was correlated with the p66 form of Dsrc28C, we made use of the transformed fly strain bearing the pCasper-hs $28 \mathrm{C}$ expression vector shown in Figure 1C. Heat-shock-induced transcripts from this gene encode only the p66 Dsrc28C protein (Fig. 4A). Only low levels of p66 protein expression from genomic Dsrc28C are detectable by the immunoblot assay in third-instar larvae (data not shown). Therefore, mAbI19 staining of tissues from third-instar larvae of the pCasper-hs $28 \mathrm{C}$ strain should represent a sensitive assay for the intracellular distribution of $\mathrm{p} 66$. The periphery of heat-shocked salivary gland cells from the pCasper-hs28C transformants (Fig. 7a) stain with mAbI19, reminiscent of the staining of early embryonic cells (Fig. 5). Staining of salivary glands from the P-element transformant alone, used as a control (Fig. 7b), yielded only background immunofluorescence equivalent to that obtained with second antibody alone. Most of what appears to be background fluorescence in the salivary gland in Figure $7 \mathrm{a}$ is due to out-of-focus peripheral mAbI19 staining.

\section{The Dsrc28C p55 protein is the cytoplasmic nervous system form}

A similar strategy was used to define the intracellular distribution of p55. Transformants bearing the pCasperhs $28 \mathrm{C}-\mathrm{S}$ expression vector produce a protein equivalent to the p55 embryonic protein (Fig. 4). The cytoplasm of heat-shocked salivary gland cells from the pCasperhs28C-S transformant stains with mAbI19 (Fig. 7c), in contrast to the peripheral staining of salivary gland cells expressing p66 (Fig. 7a).

An alternate strategy was employed to identify the form of Dsrc28C protein in the nervous system. This strategy relied on another monoclonal antibody, mAbB3, that recognizes the p66, but not p55, form of Dsrc28C. $\mathrm{mAbB} 3$ reacts with the bacterially produced forms of Dsrc28C shown in Figure 2: plac28C, pWV404, and pWV406, but not pWV405 (data not shown). mAbB3 detects the p66 protein from 10-hr embryos (Fig. 8A, lane 2) but not p55 in either 10- or 18-hr embryos (Fig. 8A, lanes 2 and 1 , respectively). That mAbB3 recognizes only the p66 form of Dsrc28C was substantiated further by the reactivity of the antibody with bacterially produced forms of Dsrc28C. Two different bacterial expression plasmids [Fig. $1 \mathrm{~B}(1),(2)]$ were used for these experiments. The major protein directed by the plac $28 \mathrm{C}$ expression vector is longer than p66 Dsrc28C due to additional amino-terminal amino acids from the expression vector [Fig. $1 \mathrm{~B}(1)$ ]. Both $\mathrm{mAbB} 3$ and $\mathrm{mAbI} 19$ react with plac28C protein (Fig. 8A, lanes 3,6 ). mAbI19 also reacts with a protein not detected by mAbB3, which could result from initiation at the $\mathrm{p} 55$ initiator methio- 
nine codon (Fig. 8A, lane 6), although the identity of this protein has not been investigated further. The expression vector diagramed in Figure $1 \mathrm{~B}(2)$ directs the synthesis of two proteins, plac28C-S and p28C-S, which differ with respect to the initiator methionine codon used. A termination codon is located midway between the initiator codon in the plasmid and the initiator codon in the cDNA. Translational termination at this codon is suppressed partially in Escherichia coli (XLlBlue) by the SupE44 mutation, which encodes an amber suppressor tRNA. Suppression results in incorporation of tyrosine at the position of the amber codon and gives rise to the longer protein referred to as plac28C-S. The shorter form, referred to as $\mathrm{p} 28 \mathrm{C}-\mathrm{S}$, is encoded solely by the truncated Dsrc28C cDNA and arises from efficient initiation at the Dsrc28C methionine codon downstream from the termination codon. Therefore, this protein is identical to p55 encoded by pCasper-hs28C-S. plac28C-S is longer than p28C-S due partially to aminoterminal amino acids from the expression vector and 15 amino acids encoded by the full-length Dsrc28C DNA directly upstream from the initiator methionine codon used by the p55 Dsrc $28 \mathrm{C}$ protein. The difference between plac28C-S and p28C-S is diagramed in Figure $8 \mathrm{~B}$. The tyrosine residue encoded by the suppressible amber codon is indicated by an asterisk (*). In wild-type E. coli, translational suppression does not occur and only the shorter p28C-S protein is synthesized upon IPTG induction (data not shown). mAbB3 and mAbI19 both react with plac28C-S (Fig. 8A, lanes 4,5). However, the critical difference between the two antibodies is that mAbI19 recognizes $\mathrm{p} 28 \mathrm{C}-\mathrm{S}$ corresponding to $\mathrm{p} 55$ but $\mathrm{mAbB} 3$ does not (Fig. 8A, lanes 4,5). Therefore, the epitope recognized by $\mathrm{mAbB} 3$ is included in the amino acid sequence S P T L L N G N G N L L D A N.

Thus, cells in the embryo staining with mAbI19, but not mAbB3, would represent cells expressing the p55 Dsrc28C protein but not the p66 Dsrc28C protein. Cells of the nervous system have exactly this pattern of staining. A population of late embryos was divided after fixation and processing and then stained with either mAbI19 or mAbB3. mAbI19 stains the central nervous system (Fig. 9a), whereas no staining of the CNS is observed with mAbB3 (Fig. 9b).

Figure 6. Indirect immunofluorescence staining of the embryonic nervous system with mAbI19. Whole Drosophila embryos were stained with mAbIl9 after removal of the chorion and vitelline membrane and subsequently stained with fluorescent second antibody. (a) Low magnification view of mAbIl9 staining of the CNS. The embryo on the right with substantial ventral nerve cord condensation is $\sim 5 \mathrm{hr}$ older than the embryo on the left. $(b)$ Ventral view of mAbI19 staining of the CNS and neurons of the PNS. (c) Lateral view of mAbIl9 staining of the $\mathrm{CNS}$ and of the lateral and dorsal groups of peripheral neurons (PN). (d, left) An embryo stained with mAbI19 and fluorescent second antibody; (right) an embryo processed in parallel with the one on the left but stained with only fluorescent second antibody.

\section{Discussion}

The Dsrc28C gene encodes two proteins: p66, predicted from the cDNA sequence, and p55, revealed by the results presented in this discussion. Two striking features of $\mathrm{p} 66$ are that it is a highly basic protein and that it has
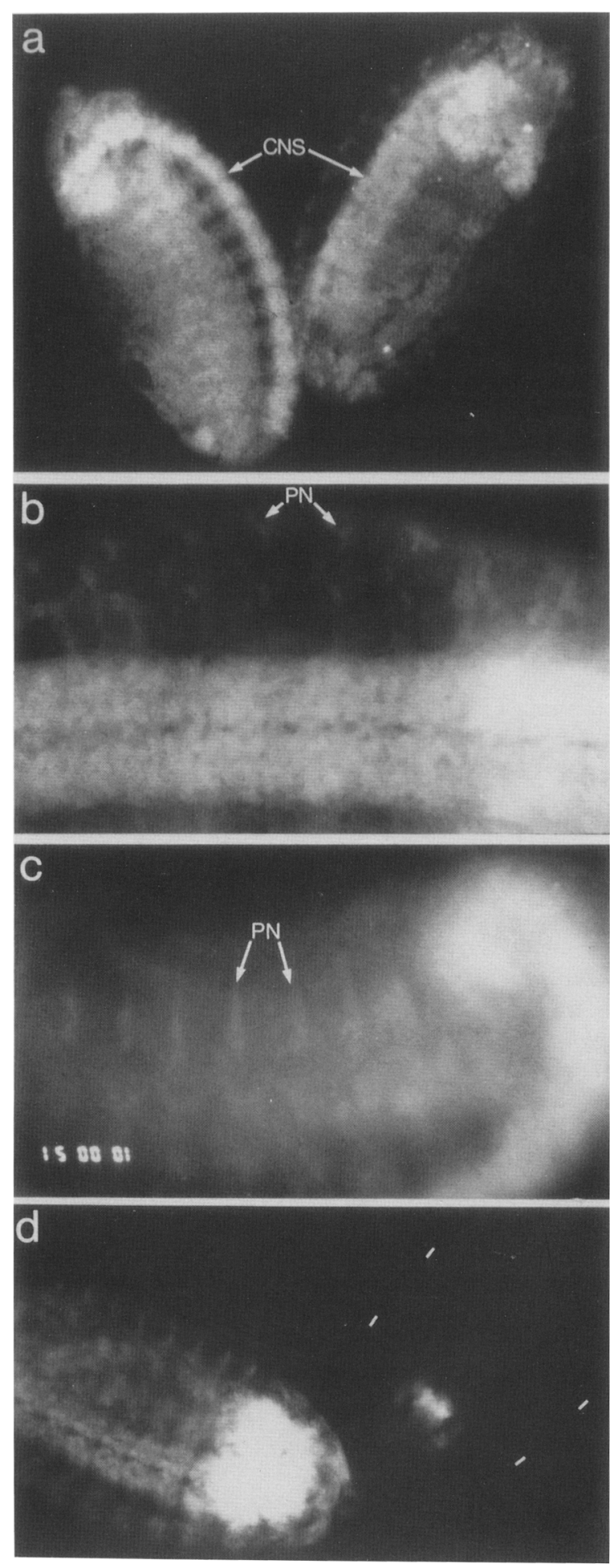

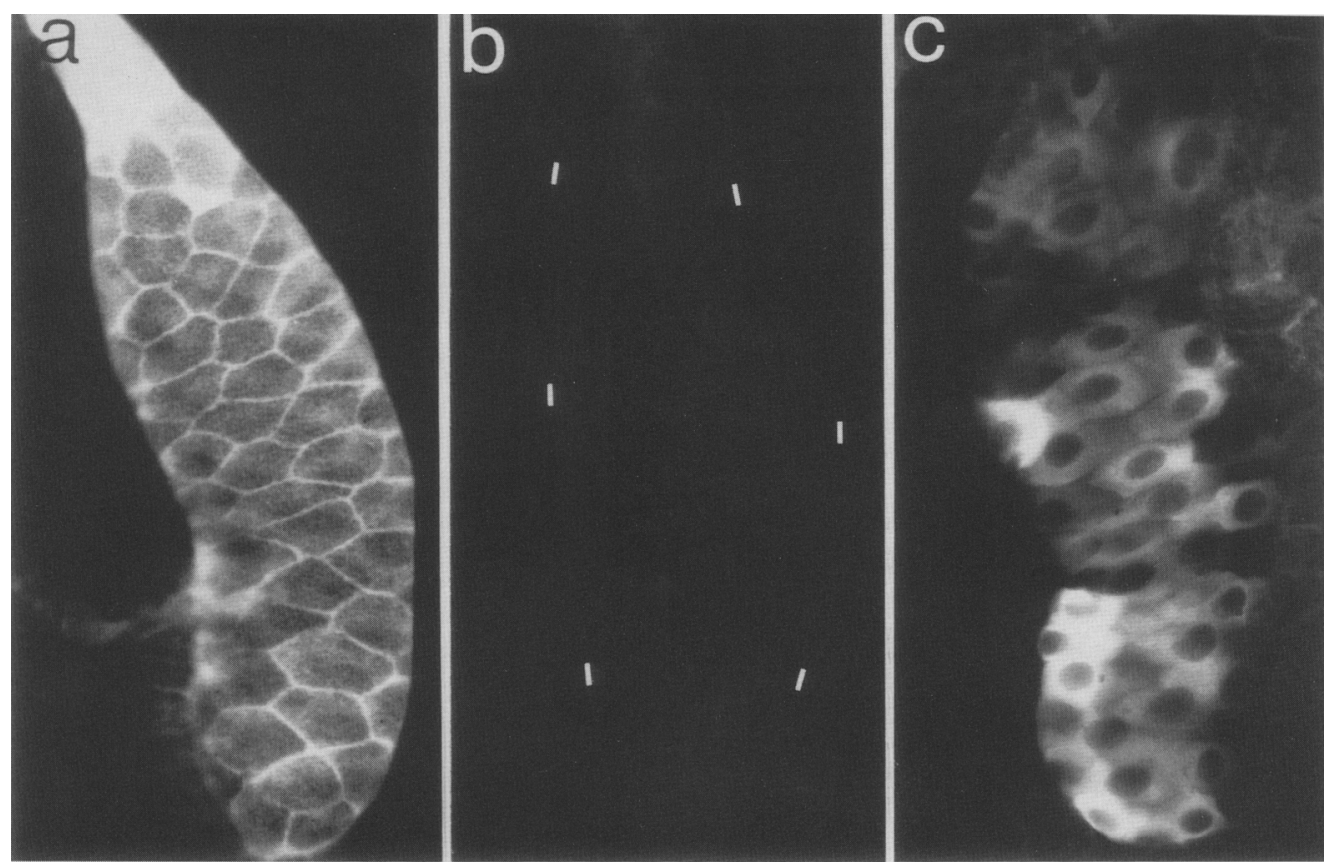

Figure 7. Intracellular localization of the p66 and p55 Dsrc28C proteins expressed in salivary glands. Third-instar larvae from either the strain bearing the pCasper-hs $28 \mathrm{C}$ construct $(a)$, a strain bearing only the Casper P element $(b)$, or a strain bearing the pCasperhs28C-S construct $(c)$ were heat shocked. Salivary glands were then dissected out, fixed, and stained with mAbIl9 under the same conditions used for embryos. The salivary glands in $a$ and $b$ were present in the same microscopic field and were photographed simultaneously. The salivary gland shown in $c$ was photographed under identical conditions.

a predominantly glycine amino-terminal domain. Analyses of p55 suggest that it lacks approximately the first 125 amino acids of $\mathrm{p} 66$. Therefore, p55 would retain the kinase domain and would still be a basic protein (pI 9.8) but would lack the glycine-rich domain.

As well as differing in their primary sequences, the two Dsrc28C proteins differ in their intracellular localization. 55 appears to be distributed throughout the cytoplasm of neuronal cells, whereas p66 localizes to the periphery within ectodermal cells. These Dsrc28C proteins, when expressed ectopically in salivary gland cells, appear to be located in regions of the cell analogous to their normal embryonic cell locations. These results suggest that some feature of the primary structure of either one or both proteins is responsible for their localization. A relatively straight forward speculation is that the amino acids uniquely present in the p 66 protein might direct the protein to the periphery of the cell. Tight association with the inner layer of the cell membrane through an amino-terminal myristic acid added posttranslationally is a property of many $s r c$ family proteins (Buss and Sefton 1985; Buss et al. 1988; Kaplan et al. 1988). We have noted before (Gregory et al. 1987) that the $\mathrm{p} 66$ protein predicted from the cDNA sequence would lack glycine in the second position, which is required for post-translational myristylation. It is interesting to note that the proteins predicted from Dsrc and
Dabl cDNA sequences have glycine as the second amino acid (Simon et al. 1985; Henkemeyer et al. 1988). For p66 to undergo conventional post-translational myristylation, cleavage of the protein to expose an amino-terminal glycine residue would have to take place. How ever, we have not seen evidence for cleavage of the $\mathrm{p} 66$ expressed from the pCasper-hs28C vector in embryos, larvae, or adults (R.J. Gregory and S.C. Wadsworth, unpubl.). To achieve localization to the cell periphery, $\mathrm{p} 66$ could interact with integral membrane proteins or could alternatively associate with components of the cell cortex.

What are the routes by which the two forms of Dsrc28C protein could be produced? Alternate splicing of a uniform Dsrc28C primary transcript in different cell types could generate two forms of mRNA with different initiator codons. Two introns are present within the genomic sequence between the first and third methionine codons: one is 64 nucleotides in length and the other is at least $5-\mathrm{kb}$ in length (Gregory et al. 1987). Splicing to remove the first Dsrc28C amino-acid-coding exon could generate an mRNA wherein the former third methionine codon is now the first in-frame methionine codon. Loss of the first exon would reduce the size of the mRNA by maximally $600-700$ nucleotides, depending on the position of the upstream splice donor. We have noted before that multiple, closely spaced Dsrc $28 \mathrm{C}$ tran- 


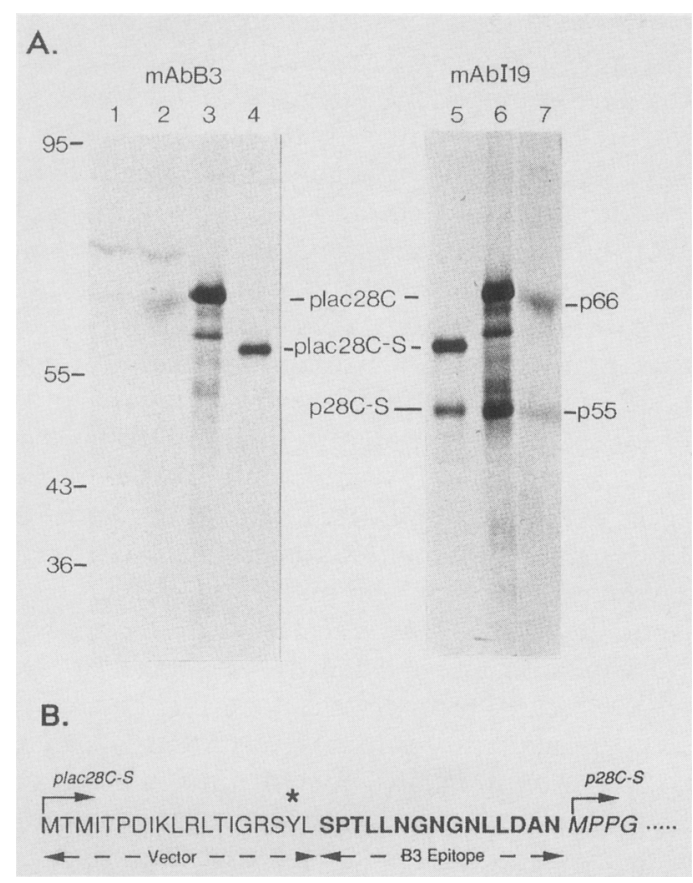

Figure 8. Specificity of mAbB3. (A) Reaction with mAbB3. (Lane 1) 16-hr-old embryo protein; (lane 2) 10-hr-old embryo protein. The identity of the $\sim 70-\mathrm{kD}$ protein detected by $\mathrm{mAbB} 3$ is unknown. (Lane 3) Protein from IPTG-induced bacteria bearing the plac $28 \mathrm{C}$ expression vector [Fig. $1 \mathrm{~B}(1)]$. The major $\mathrm{mAbB} 3$-reactive protein in lane 3 is plac28C, which is longer than the p66 Dsrc28C protein. Additional antibody-reactive proteins are presumably breakdown products of plac $28 \mathrm{C}$. (Lane 4) Protein from IPTG-induced bacteria bearing the plac $28 \mathrm{C}-\mathrm{S}$ expression vector [Fig. 1B(2)]. The only detectable mAbB3-reactive protein is plac28C-S, which is longer than the p55 Dsrc28C protein. Reaction with mAbI19. Lanes 5, 6, and 7 are identical in protein loading to lanes 4,3 , and 2. (Lane 5 ) The major mAbI19-reactive protein is plac28C-S. The other mAbI19-reactive protein is $\mathrm{p} 28 \mathrm{C}-\mathrm{S}$, which corresponds to embryonic p55 Dsrc28C protein. (Lane 6) The major mAbI19-reactive protein is plac28C. Additional antibody-reactive proteins are presumed to be breakdown products of plac28C. (Lane 7) The mAbI19reactive proteins are the $\mathrm{p} 66$ and $\mathrm{p} 55 \mathrm{Dsrc} 28 \mathrm{C}$ embryo proteins. (B) The junction region between the plasmid vector and the truncated Dsrc28C dDNA clone. The first 19 amino acids shown are encoded by the plasmid vector. The arrow labeled plac28C-S indicates the initiator methionine in the protein. When translational termination is suppressed, a tyrosine residue $\left({ }^{\star}\right)$ is incorporated into the protein at the position indicated. The arrow labeled p28C-S indicates the initiator methionine codon used for the protein $\mathrm{p} 28 \mathrm{C}$-S. In boldface type, between the above noted regions, are the Dsrc28C amino acids present in plac28C-S but not in p28C-S. Therefore, the epitope recognized by $\mathrm{mAbB} 3$ must be contained within these 15 amino acids.

scripts are observed in embryos (Gregory et al. 1987). There is ample precedent for alternate splicing in Drosophila, giving rise to variant protein products or as a mechanism for on/off regulation (Bingham et al. 1988). A germ-line-specific splice regulates whether P-element transposase or a carboxy-terminally truncated protein of unknown function is produced (Laski et al. 1986; Rio et al. 1986). A neuronal cell-specific splice, in concert with cell-specific promoter elements, has been shown to regulate the expression of alternate forms of dopa decarboxylase (Ddc) in the hypoderm and in the CNS (Morgan et al. 1986). Like the alternative splicing pathways shown for P-element transposase and Ddc, the hypothetical Dsrc28C alternative splicing events would each give rise to a unique protein that functions in a specific tissue. It is interesting to note that a neuronal-specific form of vertebrate pp60src is generated by alternative splicing (Levy et al. 1987; Martinex et al. 1987).

Other mechanisms for expression of two Dsrc28C proteins also can be envisaged. Transcription of the Dsrc28C gene could be initiated from a neuronal-specific promoter residing in the large intron downstream from the first two methionine codons. Alternate splicing would not have to be invoked in this model because the first in-frame methionine codon would be the one used
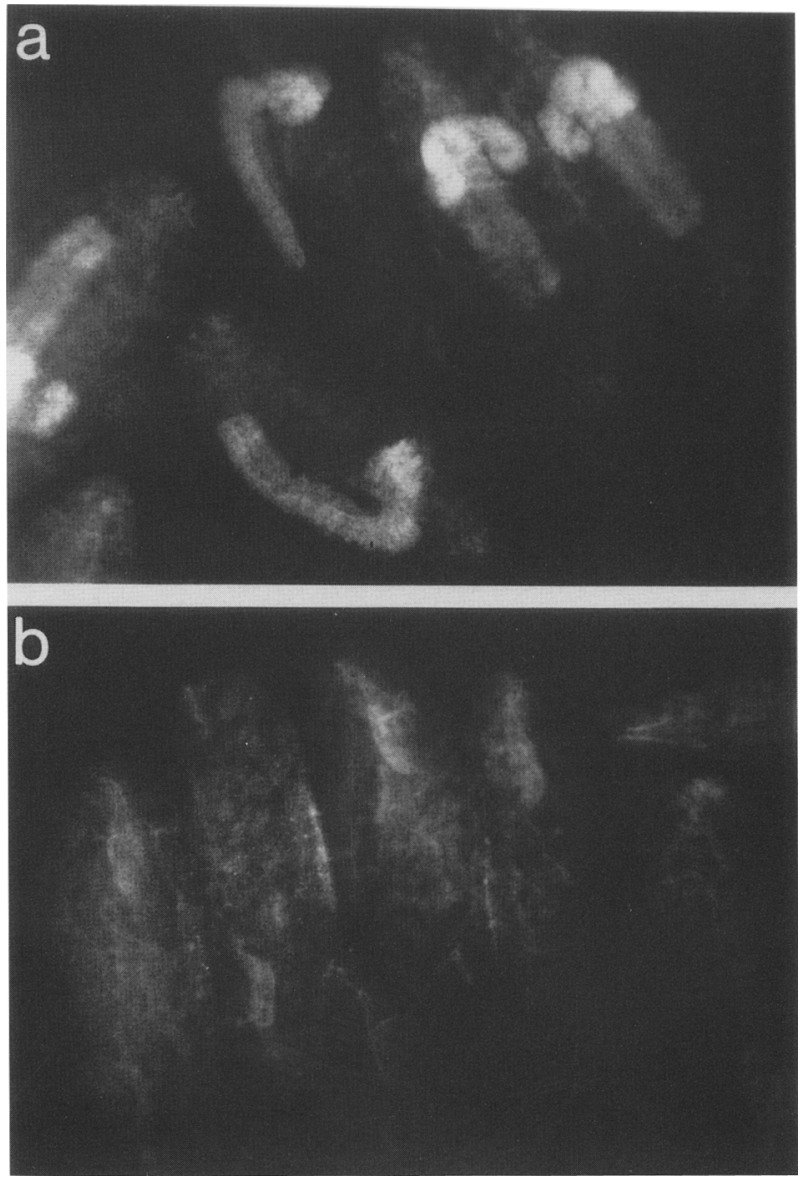

Figure 9. Differential reaction of the nervous system with mAbI19 and mAbB3. Using the conditions described in Methods, a common batch of late embryos were stained with either mAbI19 $(a)$ or with mAbB3 $(b)$. 
to initiate the p55 neuronal protein. Finally, it is also formally possible that translational initiation at the first and closely spaced second methionine codons in the mRNA could be suppressed by an unknown mechanism in neuronal cells. Isolation and characterization of Dsrc28C cDNA clones from late embryonic stages will be required to define the structure of the mRNA encoding $\mathrm{p} 55$.

Results of mAbl19 staining suggest an involvement of Dsrc28C in segmentation. From the cellular blastoderm stage until full germ-band extension, p66 is expressed in all cells of the ectoderm. Shortly thereafter, 13 or 14 stripes of p66 staining within the germ band are seen, as well as additional staining in the head region that has not been well characterized. After peak stripe expression, mAbl19 staining of the cell surface fades away rapidly by the initiation of germ-band retraction at the end of stage 11. As we have noted, highly synchronized embryo collections are required to observe a large fraction of embryos with the stripe pattern, indicating that this pattern of expression is extremely transient. As to the key questions of how the stripes arise and their relationships to known body segments, we can only speculate. The striped pattern of p66 expression could arise from selective turnover of the protein in the interstripe cells or from selective gene activation in the stripe cells. In situ hybridization experiments have not been helpful in resolving this question because Dsrc28C RNA is expressed at low levels in all cells during early embryogenesis. Similarly, the generally low level of Dsrc28C protein expression and the transient nature of the stripe pattern make it difficult to assess the number of cells participating in the stripes and to correlate the stripes with known segments. However, the number of stripes and the fact that they are distributed over the full length of the germ band suggest a correlation with embryonic parasegments (Martinez-Arias and Lawrence 1985; Scott and Carroll 1987). Simultaneous staining with antibodies specific for known segmentation gene proteins will be required to orient the Dsrc28C stripes with those defining body segment.

The pattern of expression of Dsrc28C is similar in another respect to the pattern of expression of many segmentation gene proteins. Dsrc28C and segmentation proteins are expressed in segmentally repeating patterns during early embryogenesis and appear later on in the nervous system. A clear difference, however, is that each of these segmentation genes is expressed in a small subset of segmental CNS neurons (Doe and Scott 1988), whereas Dsrc28C is expressed widely in cells within the CNS and PNS. The pattern of Dsrc28C expression is also superficially similar to that reported recently for fasciclin III, a set of closely related neuronal glycoproteins; ectodermal striped expression, followed by nervous system expression (Patel el al. 1988).

We began this study with the hypothesis that proteins encoded by the Dsrc28C gene might perform regulatory roles during embryonic development mediated through protein kinase activity. From the results presented in this discussion, it is clear that expression of the Dsrc28C gene is regulated tightly with regard to the forms of the protein expressed, the cell type expressing the different forms of the protein, and the intracellular distribution of the protein. Little is known of the gene products whose expression is controlled by segmentation genes either in the ectoderm or in the nervous system. Proteins encoded by segmentation genes are thought to be DNA-binding proteins that almost certainly initiate regulatory cascades resulting in segment specialization. It is predictable that many such downstream functions might be controlled indirectly by segmentation proteins and that controls at the protein level also might represent part of the regulatory cascade. It would obviously be premature to suggest that the complicated pattern of Dsrc $28 \mathrm{C}$ expression we have documented insignificant with respect to the regulation of development of the segmented body pattern or the nervous system. However, by analogy to other members of the $s r c$ family, it seems extremely likely that Dsrc28C proteins in ectodermal and neuronal cells serve in regulatory roles. The fact that two distinct forms of the protein exist-one within the periphery of the cell, perhaps associated with the cell membrane, and the other cytoplasmic-suggests that Dsrc28C could have two related yet distinct functions. Genetic and molecular genetic studies will be required to determine whether altered patterns of Dsrc28C expression or alterations in its primary sequence affect segmentation of nervous system development.

\section{Methods}

\section{Fly culture and collection}

D. melanogaster strain Oregon $\mathrm{R}$, and the $\mathrm{Df}(1) \mathrm{w}, \mathrm{y} \mathrm{w}^{67 \mathrm{c} 23(2)}$ strain were maintained in population cages at $25^{\circ} \mathrm{C}$. Embryos generally were collected for a 2 -hr period, following a precollection to purge females of retained fertilized eggs, and allowed to develop at $25^{\circ} \mathrm{C}$. For developmentally staged embryos, the time of development is designated from the midpoint of the collection period. Thus, a 4-hr-old embryo preparation represents embryos from 3-5 hr postegg deposition. Developmental stages are those described by Campos-Ortega and Hartenstein (1985).

\section{Plasmid construction, RNA, and protein expression}

DNA isolation, ligations, and transformations were performed using standard methods (Maniatis et al. 1982). The host for all protein expression vectors was XL1-Blue (Stratagene). Specific details on the construction of Dsrc28C expression vectors from pWV411 (restriction map shown in Fig. 1A), the original cDNA expression subclone (Gregory et al. 1987), are described below.

plac28C expression vector A 2.15-kb MluI fragment containing the entire Dsrc28C open reading frame was subcloned from pWV411 into pIBI25 to produce pRG411. Oligonucleotide-directed mutagenesis was performed on single-stranded pRG411 to introduce a Ball site 4 nucleotides upstream of the first initiator methionine in the open reading frame. Mutagenesis was performed essentially as described by Zoller and Smith (1983), except that T4 DNA polymerase was used instead of the Klenow enzyme, the reaction was treated with dam methylase to increase the efficiency of mutagenesis, and closed circular DNA was isolated by agarose gel electrophoresis. The 
single-base change creating the Ball site and the bases complementary to the initiator methionine are underlined in the oligonucleotide sequence CTTCATGTGGCCAAT. Potential mutants were screened by restriction digest. A clone containing the mutation was digested with Ball and MluI, and the 2-kb fragment containing the open reading frame was isolated and inserted into the HincII and MluI sites of pIBI24 to create the plac28C expression vector. IPTG induction of bacterial cells containing this vector resulted in the production of a $68-\mathrm{kD}$ protein found entirely in the insoluble fraction of cell lysates.

plac28C-S expression vector Oligonucleotide-directed mutagenesis of pRG411 also was used to introduce a HindIII site 50 nucleotides upstream of the third methionine of the open reading frame. The mutagenesis was performed exactly as described above using the oligonucleotide sequence GTTGGGGAAAGCTTGAAAG, where the two nucleotides directing the mutation are underlined. A clone containing the mutation was digested with HindIII and MluI and the $1.65-\mathrm{kb}$ fragment containing the majority of the open reading frame was cloned between the HindIII and MluI site of pIBI25. The resulting plasmid was then digested with HindIII, treated with Klenow enzyme and dNTPs to create blunt ends, and religated to generate plac28C-S.

$\beta$-Galactosidase-fusion vectors Fragments from pWV411 were cloned into the $\beta$-galactosidase fusion vector pWR590-1 (Guo et al. 1987) to generate a series of lacZ-Dsrc28C fusion proteins. pWV404 contains the $1.8-\mathrm{kb}$ EcoRI-HincII fragment, pWV405 contains an 800-bp BamHI-HincII fragment, and pWV406 contains an EcoRI-PstI fragment and was generated by deleting the PstI fragment internally from pWV404. Upon IPTG induction, these plasmids produce insoluble proteins of $\sim 130,000,95,000$, and 115,000 daltons, respectively.

pCasper-hs28C Drosophila Dsrc28C germ-line transformations were performed with a vector based on the Casper $\mathrm{P}$ element (kindly supplied by V. Pirrotta). A 340-bp XbaI-PstI fragment containing the hsp70 promoter was coupled to the 2.15 kb MluI fragment from Dsrc28C. A 240-bp SalI-XhoI fragment containing the polyadenylation signal from the hsp70 gene was then coupled to the $3^{\prime}$ end of the Dsrc28C MluI fragment. Short segments of polylinker from pIBI24 and pIBI25, used to facilitate the cloning, separate the three gene fragments. A $2.75-\mathrm{kb}$ $X b a I$ fragment containing all of these elements was then inserted into the $X b a I$ site of Casper. Germ-line transformations of $\mathrm{Df}(1) \mathrm{w}, \mathrm{yw}^{67 c 23(2)}$ embryos were performed essentially as described (Rubin and Spradling 1982; Spradling and Rubin 1982), using helper plasmid p25.7wc (Karess and Rubin 1984). The progeny of injected flies were scored for the presence of any eye pigmentation.

\section{Production of soluble plac28C}

Bacterial cultures containing the plac $28 \mathrm{C}$ expression vector were grown to mid-log phase, induced with $1 \mathrm{mM}$ IPTG and incubated 5-6 hr. The cells were then pelleted by centrifugation, resuspended in $200 \mathrm{mM}$ Tris- $\mathrm{HCl}(\mathrm{pH} 7.6), 250 \mathrm{mM} \mathrm{NaCl}$, $10 \mathrm{mM} \mathrm{MgCl}, 10 \mathrm{mM} \beta$-mercaptoethanol, $5 \%$ glycerol, and 0.2 $\mathrm{mg} / \mathrm{ml}$ lysozyme. After incubation at room temperature for 30 $\mathrm{min}$, the cell were subjected to two freeze-thaw cycles, sonicated to reduce viscosity, and then centrifuged to separate the soluble and insoluble cellular fractions. The insoluble pellet was then washed with $5 \mathrm{M}$ urea in $20 \mathrm{mM}$ Tris- $\mathrm{HCl}$ (pH 8.0), 5 mM EDTA, and 5\% glycerol (TEG). After centrifugation, the pellet was resuspended in TEG containing $6 \mathrm{M}$ guanidine- $\mathrm{HCl}$ and $100 \mathrm{mM} \beta$-mercaptoethanol and incubated $0.5-1 \mathrm{hr}$ at $37^{\circ} \mathrm{C}$. This solution was centrifuged to remove particulates and then diluted gradually $1: 100$ into $50 \mathrm{~mm}$ Tris- $\mathrm{HCl}(\mathrm{pH} 8.5), 50$ $\mathrm{mm} \mathrm{NaCl}, 1 \mathrm{~mm}$ EDTA, $0.1 \%$ Tween $80,1 \mathrm{~mm}$ reduced glutathione, and $0.1 \mathrm{mM}$ oxidized glutathione. After overnight incubation at $4^{\circ} \mathrm{C}$, the solution was centrifuged to remove insoluble protein and the soluble fraction was concentrated by dialysis versus $\mathrm{PEG}-8000$ or by precipitation with $50 \%$ ammonium sulfate.

\section{Antibody generation}

Dsrc28C protein for antigen was isolated from cell cultures following induction with IPTG. Insoluble plac28C protein was obtained by lysis in $7 \mathrm{M}$ guanidine $\mathrm{HCl}(\mathrm{pH} 8.0)$ and by precipitation by dilution with $10 \mathrm{~mm}$ Tris- $\mathrm{HCl}(\mathrm{pH} 7.5)$ (Guo et al. 1984). The insoluble pellet was rinsed with buffer and dissolved in SDS sample buffer at $95^{\circ} \mathrm{C}$. Following analysis on SDSPAGE (Laemmli 1970), a strip at either edge of the gel was stained with Coomassie blue and destained. The region of the remaining gel corresponding to the plac $28 \mathrm{C}$ protein was excised and protein was extracted by soaking the slice in $50 \mathrm{mM}$ Tris$\mathrm{HCl}(\mathrm{pH} 8.0), 150 \mathrm{~mm} \mathrm{NaCl}, 0.1 \mathrm{~mm}$ EDTA, $0.1 \%$ SDS, and 5 mM DTT overnight at $4^{\circ} \mathrm{C}$. The eluted material was pelleted, mixed with Freund's adjuvant and water $(1: 1)$, and sonicated to form an emulsion. Approximately $50 \mu \mathrm{g}$ of protein was used to inoculate $\mathrm{BALB} / \mathrm{c}$ mice subcutaneously. Booster injections of either the same material or total bacterial insoluble protein in Freund's incomplete adjuvant followed at 2-week intervals until the serum titer of antibody to plac $28 \mathrm{C}$ protein reached $1: 1000$ by Western blot analysis. The animals then were sacrificed for monoclonal antibody production. This antigen yielded the antibody designated mAbI19 following cloning. Alternatively, mice were injected in a similar regimen using the soluble plac28C protein fraction described above. Cloning of spleen cells from one of these mice yielded the antibody mAbB3. Hybridomas with NS-1 myeloma cells were obtained by PEG fusion and cloned according to standard procedures (Goding 1986).

\section{Protein blotting}

Proteins analyzed by SDS-PAGE were transferred to nitrocellulose in $25 \mathrm{~mm}$ ethanolamine $/ 25 \mathrm{mM}$ glycine $/ 20 \%$ methanol to facilitate elution and binding of basic proteins (Szewczyk and Kozloff 1985). The membranes were incubated in $1 \%$ gelatin in Tris-buffered saline/Tween [TTBS: $20 \mathrm{~mm}$ Tris- $\mathrm{HCl}(\mathrm{pH} 7.5)$, $100 \mathrm{mM} \mathrm{NaCl}, 0.05 \%$ Tween 20 ] for at least $30 \mathrm{~min}$ to block nonspecific binding and then rinsed in TTBS prior to reaction with antibody. Primary antibody was either cell culture supernant diluted to $1: 10$ in TTBS or affinity-purified IgG at 10 $\mu \mathrm{g} / \mathrm{ml}$ in TTBS. Second antibody was HRP-conjugated goat anti-mouse IgG (Jackson Immuno Research), $1: 2000$ in TTBS. Color development used $0.3 \%$ 4-chloro-1-napthol in $0.03 \%$ $\mathrm{H}_{2} \mathrm{O}_{2}$.

\section{Protease digestions}

V8 protease and chymotrypsin digestions in gel slices were perfomed essentially as described (Cleveland et al. 1977). The proteins indicated in the text were isolated on $8 \%$ SDS-polyacrylamide gels. For each sample, the segment of the gel containing proteins in the $66-\mathrm{kD}$ or $55-\mathrm{kD}$ range was identified by comparison with prestained electrophoresis standards in parallel lanes, excised from the gel, and soaked in stacking gel buffer for 30 
min. The gel slices were then placed in the wells of a second SDS-polyacrylamide gel $(12.5 \%$ polyacrylamide separating gell, and each gel slice was overlayed with sample buffer containing either $250 \mathrm{ng}$ of V8 protease (Miles Laboratories) or $5 \mu \mathrm{g}$ of chymotrypsin (Worthington). Electrophoresis was performed as usual, except that current was interrupted for $30 \mathrm{~min}$ when the dye front neared the bottom of the stacking gel. Subsequently, the digestion products were transferred to nitrocellulose and detected using mAbI19 as described above.

\section{Immunofluorescence}

Embryos for whole-mount immunofluorescence histology were collected for one hr, aged at $25^{\circ} \mathrm{C}$ for the appropriate time period, and rinsed with distilled $\mathrm{H}_{2} \mathrm{O}$ prior to dechorionation, fixation, and devitellinization, according to the method of Thomas et al. (1988). Primary antibody incubation was overnight at $4^{\circ} \mathrm{C}$ in phosphate-buffered saline (PBS) containing $0.1 \%$ Triton X-100 and 5\% normal goat serum (PBSTN), at the same antibody concentration as for Western blotting, followed by several rinses in PBS/Triton X (PBST) for at least $2 \mathrm{hr}$. The embryos were then incubated in secondary antibody, fluoresceinconjugated goat anti-mouse IgG (Cappel) at $1: 200$ dilution in PBSTN, at room temperature for $2 \mathrm{hr}$. The embryos were rinsed in several changes of PBST and mounted in 2.5\% 1,4-diazobicyclo- $(2,2,2)$-octane (DABCO)/90\% glycerol/PBS (Johnson et al. 1982) for microscopy.

\section{Acknowledgments}

We thank Stephen King, Bryce Paschal, and Nancy Kravit for assistance with monoclonal antibody procedures, John Goodchild for synthesizing oligonucleotides, Justin Fallon for assistance with immunofluorescence microscopy, and Vincent Pirrotta and Pay Wu for supplying plasmids. This work was supported by grants to S.C.W. from the National Cancer Institute (CA-35911) and the March of Dimes Birth Defects Foundation. W.S.V. and R.J.G. were supported by NRSA fellowships CA-08011 and GM-11772, respectively. Central research facilities were supported, in part, by grants from the National Cancer Institute (CA-12708) and the Mimi Aaron Greenberg Memorial Cancer Research Fund.

\section{References}

Banerjee, U., P.J. Renfranz, J.A. Pollock, and S. Benzer. 1987. Molecular characterization and expression of sevenless, a gene involved in neuronal pattern formation in the Drosophila eye. Cell 49: 281-291.

Basler, K. and E. Hafen. 1988. Control of photoreceptor cell fate by the sevenless protein requires a functional tyrosine kinase domain. Cell 54: 299-311.

Beach, D., B. Durkacz, and P. Nurse. 1982. Functionally homologous cell cycle control genes in fission yeast and budding yeast. Nature 300: 706-709.

Bingham, P.M., T.-B. Chou, I. Mims, and Z. Zacher. 1988. On/ off regulation of gene expression at the level of splicing. Trends Genet. 4: 134-138.

Buss, J.E. and B.M. Sefton. 1985. The rare fatty acid, myristic acid, is the lipid attached to the transforming protein of Rous sarcoma virus and its cellular homolog. I. Virol. 53: 7-12.

Buss, J.E., C.J. Der and P.A. Solski. 1988. The six amino-terminal amino acids of $\mathrm{p} 60$ src are sufficient to cause myristylation of p21'ras. Mol. Cell. Biol. 8: 3960-3963.

Campos-Ortega, J.A. and V. Hartenstein. 1985. The embryonic development of Drosophila melanogaster. Springer-Verlag, New York.

Cavener, D.R. 1987. Comparison of the consensus sequence flanking translational start sites in Drosophila and vertebrates. Nucleic Acids Res. 15: 1353-1361.

Cleveland, D.W., S.G. Fisher, M.W. Kirchner, and U.K. Laemmli. 1977. Peptide mapping by limited proteolysis in sodium dodecyl sulfate and analysis by gel electrophoresis. I. Biol. Chem. 252: 1102-1106.

Doe, C.Q. and M.P. Scott. 1988. Segmentation and homeotic gene function in the developing nervous system of Drosophila. Trends Neurosci. 11: 101-106.

Goding, J.W. 1986. Monoclonal antibodies: Principles and practice. Academic Press, New York.

Gregory, R.J., K.L. Kammermeyer, W.S. Vincent III, and S.C. Wadsworth. 1987. Primary sequence and developmental expression of a novel Drosophila melanogaster src gene. Mol. Cell. Biol. 7: 2119-2127.

Guo, L.-H., P.P. Stepien, J.T. Tso, R. Brousseau, S. Narang, D.Y. Thomas, and R. Wu. 1984. Synthesis of human insulin gene. VIII. Construction of expression vectors for fused proinsulin production in Escherishia coli. Gene 29: 251-254.

Hafen, E., K. Basler, J.-E. Edstrom, and G. Rubin. 1987. sevenless, a cell-specific homeotic gene of Drosophila, encodes a putative transmembrane receptor with a tyrosine kinase domain. Science 236: 55-63.

Hanks, S.K., A.M. Quinn, and T. Hunter. 1988. The protein kinase family: conserved features and deduced phylogeny of the catalytic domains. Science 241: 42-52.

Henkemeyer, M.J., R.L. Bennett, R.B. Gertler, and F.M. Hoffmann. 1988. DNA sequence, structure, and tyrosine kinase activity of the Drosophila melanogaster Abelson proto-oncogene homolog. Mol. Cell. Biol. 8: 843-853.

Jan. L.Y. and Y.N. Jan. 1982. Antibodies to horseradish peroxidase as specific neuronal markers in Drosophila and in grasshopper embryos. Proc. Nat1. Acad. Sci. 72: 2700-1704.

Johnson, G.D., R.S. Davidson, K.C. McNamee, G. Russel, D. Goodwin, and E.J. Holborow. 1982. Fading of DABCO for FITC quench inhibition of immunofluorecence during microscopy: A study of the phenomenon and its remedy. $J . \mathrm{Im}$ munol. Methods 55: 231-242.

Kaplan, J.M., G. Mardon, J.M. Bishop, and H.E. Varmus. 1988. The first seven amino acids encoded by the v-src oncogene act as myristylation signal: lysine 7 is a critical determinant. Mol. Cell. Biol. 8: 2435-2441.

Karess, R.E. and G.M. Rubin. 1984. Analysis of P transposable element functions in Drosophila. Cell 38: 135-146.

Kozak, M. 1987. An analysis of $5^{\prime}$-noncoding sequences from 699 vertebrate messenger RNAs. Nucleic Acids Res. 15: $8125-8148$.

Laemmli, U.K. 1970. Cleavage of structural proteins during the assembly of the head of bacteriophage T4. Nature 227: 680685.

Laski, F.A., D.C. Rio, and G.M. Rubin. 1986. Tissue specificity of Drosophila P element transposition is regulated at the level of mRNA splicing. Cell 44: 7-19.

Levy, B., T. Dorai, L.-H. Wang, and J.S. Brugge. 1987. The structurally distinct form of pp60c-src detected in neuronal cells is encoded by a unique c-src mRNA. Mol. Cell. Biol. 7: $4142-4145$.

Lorincz, A.T. and S.I. Reed. 1984. Primary structure homology between the product of yeast cell division control gene CDC28 and vertebrate oncogenes. Nature 307: 183-185.

Maniatis, T.E., E.F. Fritsch, and J. Sambrook. 1982. Molecular cloning: A labaoratory manual. Cold Spring Harbor Laboratory, Cold Spring Harbor, New York. 
Martinez, R., B. Mathey-Prevot, A. Bernards, and D. Baltimore. 1987. Neuronal pp60c-src contains a six-amino acid insertion relative to its non-neuronal counterpart. Science 237: 411-415.

Martinez-Arias, A. and P.A. Lawrence. 1985. Parasegments and compartments in the Drosophila embryo. Nature 313: 639642.

Morgan, B.A., W.A. Johnson, and J. Hirsh. 1986. Regulated splicing produces different forms of dopa decarboxylase in the central nervous system and hypoderm of Drosophila melanogaster. EMBO I. 5: 3335-3342.

Patel, N.H., P.M. Snow, and C.S. Goodman. 1988. Characterization and cloning of Fasciclin III: A glycoprotein expressed on a subset of neurons and axon pathways in Drosophila. Cell 48: 975-988.

Reed, S.I., J.A. Hadwiger, and A.T. Lorincz. 1985. Protein kinase activity associated with the product of the yeast cell division cycle gene CDC28. Proc. Natl. Acad. Sci. 82: 40554059.

Rio, D.C., F.A. Laski, and G.M. Rubin. 1986. Identification and immunochemical analysis of biologically active Drosophila P element transposase. Cell 44: 21-32.

Rubin, G.M. and A. Spradling. 1982. Genetic transformation of Drosophila with transposable element vectors. Science 218: 348-353.

Scott, M.P. and S.B. Carroll. 1987. The segmentation and hoemotic gene network in early Drosophila development. Cell 51: 689-698.

Simon, M.A., T.B. Kornberg, and J.M. Bioshop. 1985. The nucleotide sequence and tissue-specific expression of Drosophila c-src. Cell 42: 831-840.

Spradling, A. and G.M. Rubin. 1982. Transposition of cloned P element into Drosophila germ line chromosomes. Science 218: $343-347$.

Szewczyk, B. and L.M. Kozloff. 1985. A method for the efficient blotting of strongly basic proteins from sodium dodecyl sulfate-polyacrylamide gels. Anal. Biochem. 150: 403-407.

Thomas, B., S.T. Crews, and C.S. Goodman. 1988. Molecular genetics of the single-minded locus: A gene involved in the development of the Drosophila nervous system. Cell 52: $133-141$.

Tomlinson, A. and D.F. Ready. 1986. Sevenless: a cell-specific homeotic mutation of the Drosophila eye. Science 231: 400-402.

Van Beveren, D. and I.M. Verma. 1986. Homology among oncogenes. Curr. Top. Microbiol. Immunology 123: 91-98.

Wadsworth, S.C., K. Madhavan, and D. Bilodeau-Wentworth. 1985. Maternal inheritance of transcripts from three Drosophila src-related genes. Nucleic Acids Res. 13: 2153-2170.

Zoller, M.J. and M. Smith. 1983. Oligonucleotide-directed mutagenesis of DNA fragments cloned into M13 vectors. Methods Enzymol. 100: 468-500. 


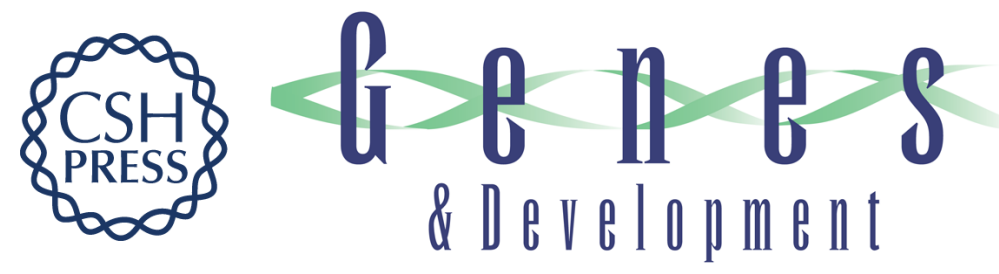

\section{Embryonic expression of a Drosophila src gene: alternate forms of the protein are expressed in segmental stripes and in the nervous system.}

W S Vincent, R J Gregory and S C Wadsworth

Genes Dev. 1989, 3:

Access the most recent version at doi:10.1101/gad.3.3.334

References This article cites 39 articles, 13 of which can be accessed free at: http://genesdev.cshlp.org/content/3/3/334.full.html\#ref-list-1

License

Email Alerting Service

Receive free email alerts when new articles cite this article - sign up in the box at the top right corner of the article or click here.

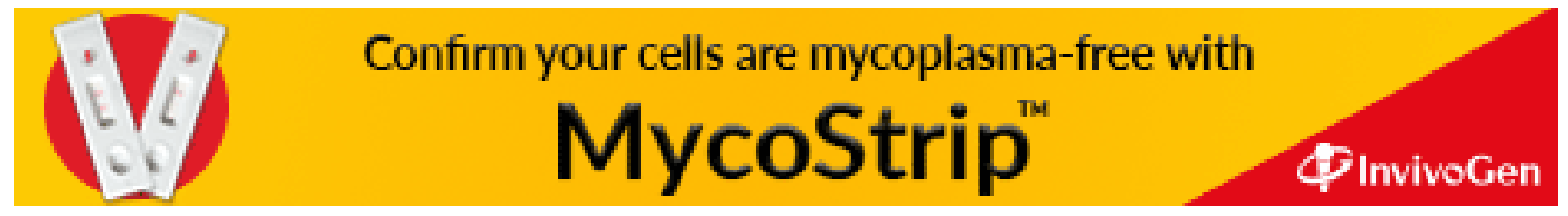

